\title{
PREVALENCE OF HEMORRHAGIC SEPTICEMIA IN CATTLE AND BUFFALOES IN TANDOJAM, SINDH, PAKISTAN
}

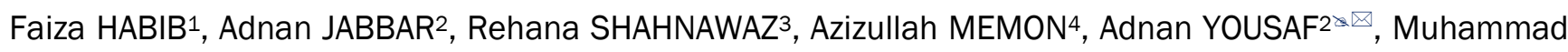 \\ BILAL $^{1}$, Tahseen JAMIL ${ }^{5}$, Rabia KHALIL ${ }^{2}$ and Adeela SHARIF ${ }^{2}$ \\ ${ }^{1}$ Department of Livestock and Dairy Development Quetta, Baluchistan, Pakistan \\ 2Salman Poultry (Pvt) Limited, Rawalpindi, Pakistan \\ ${ }^{3}$ Department of Veterinary Pharmacology, Sindh Agriculture University Tandojam, Pakistan \\ ${ }^{4}$ Department of Poultry Husbandry, Sindh Agriculture University Tandojam, Pakistan \\ ${ }^{5}$ Department of Animal quarantine, Karachi, Pakistan \\ Email: dr.adnan011@gmail.com
}

\begin{abstract}
The current study was performed to evaluate the prevalence of hemorrhagic septicemia (HS) in cattle and buffaloes in Tandojam Pakistan. The average geometric mean titers (GMT) recorded against HS in diseased buffaloes and cattle were 5.7 and 6.1, respectively. The morbidity, mortality and case fatality rates were $57.58,52.30$ and $90.83 \%$ in young buffalo calves; and $3.17,1.92$ and $60.65 \%$ in adult buffaloes, respectively. In case of young cattle calves, morbidity, mortality and case fatality rates were $8.63,5.27$ and $61.11 \%$, respectively, while in adult cattle, these values were $4.83,2.18$ and $45.23 \%$, respectively. The present study revealed that the mortality, morbidity and case fatality rates due to HS were greater in young calves than the adults both in buffaloes and cattle. Furthermore, buffaloes were found to be more susceptible to the disease than the cattle.
\end{abstract}

Keywords: Buffaloes, Cattle, Hemorrhagic septicemia, Prevalence, Tandojam

\section{INTRODUCTION}

Hemorrhagic septicemia (HS) has a wide distribution particularly in tropical countries. In Asia, HS epidemics may occur as an alarming and devastating disease in cattle and buffaloes, jeopardizing the economic return of the animal to a dangerous extent (Benkirane and De Alwis, 2012). Buffaloes are considered to be more susceptible than the cattle. It is an acute pasteurellosis manifested by a highly fatal septicemia with the causative agent being Pasteurella multocida serotype B: 2 (Wijewardana, 2014). Radical changes in weather, including the advent of monsoon, debility caused by seasonal level of low nutrition and work pressure are some of the predisposing factors which ignite the occurrence of the disease in Pakistan (Farooq et al., 2007). Clinical manifestations include high rise in body temperature $\left(104-108^{\circ} \mathrm{F}\right)$, respiratory distress, nasal discharge, salivation, tongue protrusion, reluctance to move, development of hot painful swelling and edema on throat, brisket or occasionally forelegs.

Studies on the prevalence of HS have been carried out in other regions of the world extensively (Zyambo et al., 2015; Dutta et al., 2016; Molina et al., 2014). However, keeping in view scanty work documented from Pakistan (Sheikh et al., 2016; Khan et al., 2006; Khan et al., 2011), the present study was executed to know prevalence of HS in buffaloes and cattle in Tandojam, Pakistan.

\section{MATERIALS AND METHODS}

\section{Ethical approval}

This experiment was performed considering to all animal rights (Society for Protection and Care of Animals. Sindh Agriculture University Tandojam, Pakistan)

\section{Selection of site}

An active surveillance was undertaken to understand the prevalence of HS in 10 villages of Tandojam, Pakistan The overall climate of the town is dry with scanty rain fall. The winter is not very cold and the climate is hot during the remaining part of the year, but it is very hot in summer. The temperature during summer is usually about $47^{\circ} \mathrm{C}$ while during winter season the mercury goes down as far as $10^{\circ} \mathrm{C}$. The summer season of the town usually touches the one of the highest point of temperature in Pakistan. 


\section{Experimental animals}

Ten villages with the infection/outbreak of HS in Tandojam were randomly selected to study surveillance in order to estimate the prevalence. A total of $n=4248$ animals (2963 buffaloes and 1285 cattle) from these villages were further divided into young (below 1 year) and adult (above 1 year) animals both for buffalo and cattle. Each homestead was visited from door to door in all villages and the relevant information regarding the affected animals (morbidity, mortality and case fatality rates) was recorded on a questionnaire. For comparison purposes, 10 villages (control) free of infection in the same district were also surveyed.

Table 1 - Comparative GMT values against HS in buffaloes and cattle

\begin{tabular}{|c|c|c|c|c|c|c|c|c|c|c|c|c|}
\hline \multirow{2}{*}{ Species } & \multirow{2}{*}{ Group } & \multicolumn{11}{|c|}{ Distribution of animals on basis of HS titer } \\
\hline & & $2-0$ & $2-1$ & $2-2$ & $2-3$ & $2-4$ & $2-5$ & $2-6$ & $2-7$ & $2-8$ & $2-9$ & GMT \\
\hline \multirow{2}{*}{ Buffaloes } & Affected & 11 & 15 & 19 & 31 & 17 & 5 & 2 & 0 & 0 & 0 & 5.7 \\
\hline & Healthy & 0 & 0 & 0 & 9 & 23 & 28 & 32 & 5 & 3 & 0 & 34.3 \\
\hline \multirow{2}{*}{ Cattle } & Affected & 8 & 11 & 24 & 22 & 25 & 7 & 3 & 0 & 0 & 0 & 6.1 \\
\hline & Healthy & 0 & 0 & 2 & 11 & 19 & 31 & 29 & 8 & 0 & 0 & 32.0 \\
\hline
\end{tabular}

\section{Blood collection and serological analysis}

Blood samples $(6 \mathrm{ml})$ without anticoagulant were collected from HS affected 100 buffaloes and cattle each. Matched samples from 100 healthy buffaloes and cattle each were also collected which served as control. Serum from each sample was decanted and stored at $-20^{\circ} \mathrm{C}$ until analysis. Antibodies against Pasteurella multocida were measured by indirect haemagglutination test (IHA) using human blood group 'O' (Bain et al., 2002). Briefly, two fold dilutions of the test sera starting from 1:5 to 1:640 were made in normal saline using micro titer plates (96 wells) and added $25 \mu \mathrm{l}$ amounts to all the wells of plate except those of column 11 and 12 which served as control. First four wells (A-D) of column 11 were added with known negative serum and last four wells (E-H) with the known positive serum. Sensitized RBC's (1\%) were added in equal amounts (25 $\mu \mathrm{l})$ to all the wells of the plate, so that column 12 served as control for the RBC's.

The plates were incubated at room temperature for two hours and the observations were recorded. Thereafter, the plates were kept re-incubated under refrigeration for overnight, shaken vigorously, allowed to resettle and were read again. Results were interpreted as positive (no bead formation) or negative (bead formation with sharp clear margins). The IHA antibody titers against HS were converted into geometric mean titers (GMT) for each group (Burgh, 2008).

\section{Statistical analysis}

All data were analyzed by using Statistical Analysis System package software (SAS version 9.2, SAS Institute Inc., Cary, NC, USA). The animals (buffalo and cattle) were divided into two age groups i.e. young and adult. Data thus collected regarding mortality, morbidity and case fatality were subjected to Chi square analysis.

\section{RESULTS AND DISCUSSION}

Hemorrhagic septicemia is a disease of utmost economic importance particularly in Asia where the susceptible animal population consists of 432 million cattle and 146 million buffaloes, which constitutes 30 and $95 \%$ of the world's cattle and buffalo population, respectively (FAO, 2016). In India, during the past four decades, HS is documented to be responsible for 45$55 \%$ of all bovine deaths. During the 18 years period from 1998 to 2016, it accounted for $58.7 \%$ of the aggregate of deaths due to five endemic diseases, viz. foot-and-mouth disease (FMD), rinderpest, black quarter, anthrax and HS (Dutta et al., 2016). In an active surveillance study in Sri Lanka, it was shown that in the 1990's, around 15\% buffaloes and 8\% cattle died of HS annually (Alwis and Vipulasiri, 2001). Similarly, 34.4\% of all deaths in susceptible stock (Sheikh et al., 2016) and $31.48 \%$ mortality have been reported in buffalo calves (Khan et al., 2011) in Pakistan. The results of this study also clearly indicate that HS is a vital hurdle in the economic uplift of the livestock sector with high incidence rates and alarming morbidity, mortality and case fatality rates. In the present study, the comparative values of GMT against HS, deducted through IHA test, both for buffaloes and cattle are presented in table 1. It was noticed that the GMT value was 5.7 for affected buffaloes in comparison to 34.3 in healthy ones. Similarly, it was 6.1 in affected cattle in contrast to 32.0 in healthy ones. Hence, in diseased buffaloes, the titer was lesser as compared to diseased cattle making them more susceptible to the disease. These results are in line with the findings of Alwis et al. (2001) who have reported a higher GMT values for cattle as compared to those for buffaloes.

Similarly, the mean GMT values of 4.12 and 64.41 for affected and recovered animals have been reported by Khan et al. (2006). In the total population of 4248 animals from 10 infected/outbreak villages, the overall morbidity, mortality and case fatality rates were $17.39,14.66$ and $84.30 \%$, respectively with buffaloes having significantly higher values as compared to cattle (Table 2). In buffalo population, the morbidity, mortality and case fatality rates were $22.30,19.64$ and $88.04 \%$, respectively; however, for the cattle population, these values were $6.07,3.19$ and $52.56 \%$, respectively. These results are in accordance with those of Alwis (2001), who documented overall mortality rate of $\mathbf{4 5 . 2}$ and $\mathbf{1 5 . 8 \%}$ for buffaloes and cattle, respectively. Similarly, Sheikh et al. (2016) have also documented $9 \%$ mortality and $78 \%$ case fatality rates of HS in buffaloes, whereas these values were 2.5 and $62 \%$ in cattle. A mortality rate of $31 \%$ has been reported in buffaloes by Suhail et al. (2003) in North Waziristan Agency, Pakistan. Radostits et al. (2005) have reported that the overall mean case fatality for buffaloes is nearly three times as 
high as in cattle. Buffalo has been considered the most susceptible animal to HS throughout the world with highest incidence, morbidity, mortality and case fatality rates. Perhaps, the genetic makeup of the buffalo makes it an ideal host for the causative parasite hence increasing its susceptibility to the disease. Young stock of both buffaloes and cattle was more affected as compared to the adult ones (Table 3). The morbidity, mortality and case fatality rates were significantly higher in young stock. In buffaloes, these values were $57.58,52.30$ and $90.83 \%$ for calves; and $3.17,1.92$ and $60.65 \%$, for adult buffaloes, respectively.

Similarly, in case of cattle, the calves had the morbidity, mortality and case fatality rates of $8.63,5.27$ and $61.11 \%$, respectively in comparison to the values of $4.83,2.18$ and $45.23 \%$ for adult cattle. These findings coincide with those of Khan et al. (2006), who have also reported that the young stock of both buffaloes and cattle have higher morbidity, mortality and case fatality rates as compared to the older ones. The exhaustion of the maternal immunity against HS after the 60th day of life and delayed vaccination might be attributed to the higher susceptibility of the young calves (Mahmood et al., 2007).

\section{Table 2 - Overall morbidity, mortality and case fatality in buffaloes and cattle affected with HS}

\begin{tabular}{|c|c|c|c|c|}
\hline Species & Population (n) & Morbidity & Mortality & Case fatality \\
\hline Buffalo & 2963 & $\begin{array}{c}661 \\
(22.30 \%)\end{array}$ & $\begin{array}{c}582 \\
(19.64 \%)\end{array}$ & $\begin{array}{c}79 \\
\text { (88.04\%) }\end{array}$ \\
\hline Cattle & 1285 & $\begin{array}{c}78 \\
(6.07 \%)\end{array}$ & $\begin{array}{c}41 \\
(3.19 \%)\end{array}$ & $\begin{array}{c}37 \\
(52.56 \%)\end{array}$ \\
\hline Total & 4248 & $\begin{array}{c}739 \\
(17.39 \%)\end{array}$ & $\begin{array}{c}623 \\
(14.66 \%)\end{array}$ & $\begin{array}{c}116 \\
(84.30 \%)\end{array}$ \\
\hline P Value & & 0.05 & 0.05 & 0.001 \\
\hline
\end{tabular}

Table 3 - Morbidity, mortality and case fatality in buffaloes and cattle affected with HS according to their age

\begin{tabular}{lccccc} 
Species & Age & Population $(\mathrm{n})$ & Morbidity & Mortality & Case Fatality \\
\hline \multirow{2}{*}{ Buffalo } & Young & 1042 & $600(57.58 \%)$ & $545(52.30 \%)$ & $55(90.83 \%)$ \\
& Adult & 1921 & $61(3.17 \%)$ & $37(1.92 \%)$ & $24(60.65 \%)$ \\
\cline { 2 - 6 } Cattle & Young & 417 & $36(8.63 \%)$ & $22(5.27 \%)$ & $14(61.11 \%)$ \\
& Adult & 868 & $42(4.83 \%)$ & $19(2.18 \%)$ & $23(45.23 \%)$ \\
P Value & & & 0.20 & 0.70 & 0.50 \\
\hline
\end{tabular}

\section{CONCLUSIONS}

It can be concluded that HS is endemically occurring in cattle and buffaloes. Buffaloes are more susceptible to the disease as compared to the cattle. However, the young stock of both is highly affected in terms of morbidity, mortality and case fatality of HS as compared to the adult ones. It is highly recommended that department of livestock should give attention toward such disease in this area to control such huge economical loss.

\section{DECLARATIONS}

\section{Competing interests}

The authors have declared that no competing interest exists.

\section{Consent to publish}

The author(s) grant(s) the publisher the sole and exclusive license of the full copyright in the contribution. Consequently, the publisher shall have the exclusive right throughout the world to publish and sell the contribution in all languages, in whole or in part, including, without limitation, any abridgement and substantial part thereof, in book form and in any other form including, without limitation, mechanical, digital, electronic and visual reproduction, electronic storage and retrieval systems, including internet and intranet delivery and all other forms of electronic publication now known or here in after invented.

\section{Author's contribution}

Dr. Faiza Habib was the main researcher, Dr. Rehana Shahnawaz was research coordinator, Dr. Azizullah Memon was study supervisor, Dr. Adnan Yousaf did all correspondence of this article, Dr. Adnan Jabbar and Dr. Muhammad Bilal Muhammad revised the article, Dr. Tahseen Jamil contributions in statistics, Dr. Rabia Khalil and Dr. Adeela Sharif assisted in results analysis and other activities related to the research.

\section{REFERENCES}

Bain RVS, Alwis MCL De, Carter GR and Gupta BK (2002). Hemorrhagic septicemia. FAO Animal Production and Health Paper No. 33, Rome, Italy. 
Benkirane A and Alwis, MCL De (2012). Hemorrhagic septicemia, its significance, prevention and control in Asia. Vet Med-Czech, 47: 234-240.

Burgh MA, (2008). Simple method for recording and analyzing serological data. Avian Dis, 2: 362-365.

Alwis De MCL and Vipulasiri AA, (2001). An epizootiological study of hemorrhagic septicemia in Sri Lanka. Ceylon Vet J, 28: 2435.

Alwis De MCL, Wijewardana TG, Sivaram A and Vipulasiri AA, (2001). The carrier antibodies status of cattle and buffaloes exposed to hemorrhagic septicemia. Ceylon Vet J, 34: 33-42.

Alwis MCL De, (2001). Mortality among cattle and buffaloes in Sri Lanka due to hemorrhagic septicemia. Trop Anim Health Prod, 13: 195-202.

Dutta J, Rathore BS, Mulick SG, Singh R and Sharma GC, (2016). Epidemiological studies on occurrence of hemorrhagic septicemia in India. Indian Vet J, 67: 893-899.

FAO, (2016). Production Yearbook (2016), FAO, Statistics Division, Rome, Italy. 